\title{
Sérgio Adorno: Reflexões sobre a violência e a intolerância na sociedade brasileira
}

\author{
Cláudia Nonato \\ Jornalista, doutora em Ciências da Comunicação pela ECA-USP e editora executiva da \\ revista Comunicação \& Educação. Professora da FIAM-FAAM e pesquisadora do Centro de \\ Pesquisa em Comunicação e Trabalho (CPCT/ECA-USP). \\ E-mail: claudia.nonato@uol.com.br
}

Resumo: Referência nos estudos sobre violência, Sérgio Adorno é cientista social e doutor em Sociologia pela Universidade de São Paulo, com pós-doutorado pelo Centre de Recherches Sociologiques sur le Droit et les Institutions Pénales, França. Atualmente é professor titular e diretor da Faculdade de Filosofia, Letras e Ciências Humanas da USP e coordenador científico do NEV (Núcleo de Estudos da Violência da USP). É também representante da Comunidade Científica no Conselho Deliberativo do CNPq. Nesta entrevista, Adorno reflete sobre questões que incomodam a sociedade brasileira: o crescimento exacerbado da violência e da intolerância, em todas as esferas; a ambiguidade dos meios de comunicação nesse processo; a discussão em torno da redução da maioridade penal, e o papel da escola. Para ele, a situação da violência no país é grave e tende a piorar, por falta de planejamento estratégico do Estado.

Palavras-chave: violência; intolerância; redução da maioridade penal; Núcleo de Estudos da Violência; Sergio Adorno.
Abstract: Reference in the study of violence, Sérgio Adorno is a social scientist and a $\mathrm{PhD}$ in sociology from the University of São Paulo, with postdoctoral fellowship at Centre de Recherches Sociologiques sur le Droit et les Institutions Pénales, France. He is currently professor and director at School of Philosophy, Language and Human Sciences of USP and scientific coordinator of The Center for Studies of Violence of USP (NEV). $\mathrm{He}$ is also representative of the scientific community on the Advisory Board of the CNPq. In this interview, Adorno reflects on issues that disturb the Brazilian society: the overgrowth of violence and intolerance, in all areas; the ambiguity of the media in this process; the discussion on the reduction of the age of criminal responsibility, and the role of the school. For him, the situation of violence in the country is serious and likely to get even worse due to lack of strategic planning from the government.

Keywords: violence; intolerance; reduction of the age of criminal responsibility; Center for Studies of Violence; Sergio Adorno.

Estamos observando uma crescente e inquietante manifestação do que vem sendo chamado de "incitação ao ódio", ou "discurso do ódio" na sociedade brasileira. São protestos verbais, linchamentos morais e físicos, exacerbação da intolerância e violações dos Direitos Humanos, entre outros atos que aparecem com muita frequência, principalmente na mídia. Segundo o estudo da ONG 
Article $19^{1}$ sobre o tema, no Brasil esse tipo de discurso "é o que visa à promoção do ódio e incitação a discriminação, hostilidade e violência contra uma pessoa ou grupo em virtude de raça, religião, nacionalidade, orientação sexual, gênero, condição física ou outra característica de um determinado grupo". Embora não seja recente, é inegável que tal prática tenha sido potencializada pelas redes sociais, como demonstra outra pesquisa, lançada pela Organização das Nações Unidas para Educação, a Ciência e Cultura² (Unesco), desenvolvida em cooperação com o Programa em Direito de Mídia Comparado e Política (PCMLP) da Universidade de Oxford. O estudo caracteriza o discurso on-line e algumas das medidas que foram adotadas para combatê-lo e atenuá-lo, destacando as boas práticas que surgiram nos níveis locais e globais.

A dimensão que esses discursos on-line alcançam, e o dano potencial que podem provocar no processo democrático são preocupantes. Além disso, os fatos demonstram que tais discursos, tanto virtuais quanto físicos, representam um crescimento da violência. Um dos principais pesquisadores e especialistas do tema no país, o cientista social e coordenador do Núcleo de Estudos da Violência (NEV) da Universidade de São Paulo, Sérgio Adorno, nos aponta nesta entrevista os tipos de violência urbana mais comuns, além de mostrar a relação delas com a intolerância e com os meios de comunicação. Também analisa, entre outros temas, o debate em torno da redução da maioridade penal no processo de controle da violência.

1. Disponível em: <http:// artig019.org/centro/files/ discurso_odio.pdf>

2. Disponível em: <http:// unesdoc.unesco.org/ images/0023/002332 /233231e.pdf>.

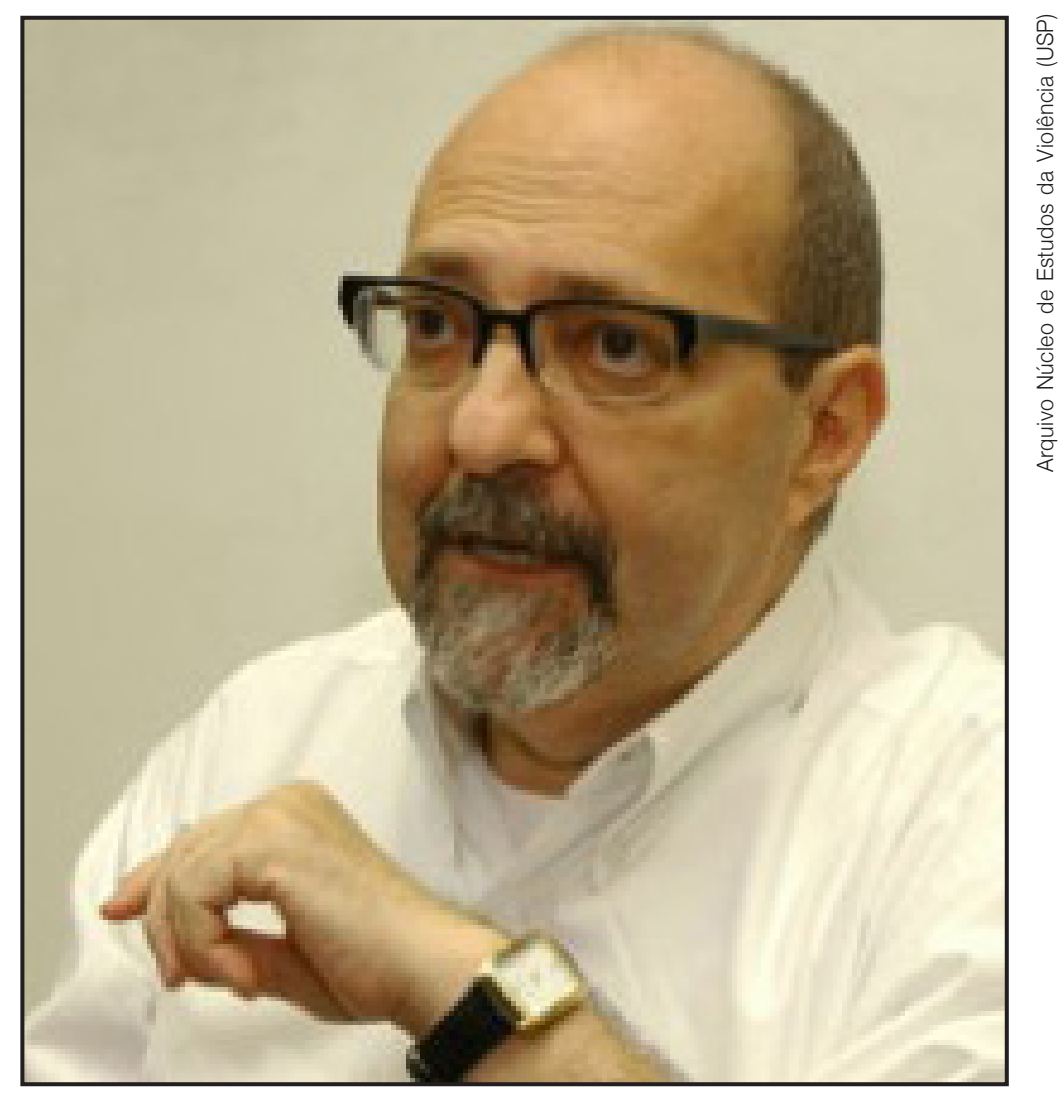


Comunicação $\mathcal{E}$ Educação: A violência urbana é tema constante das rodas de conversa. Mas pouco se sabe sobre os motivos, os dados e as consequências da violência. $O$ que o senhor pode nos esclarecer sobre esse assunto?

Sergio Adorno: Quando se fala em violência, na verdade tem que se perguntar de que violência se está falando. É muito comum que, em geral, no debate, se reduza a questão da violência ao problema do crime cotidiano, os roubos, furtos, extorsões mediante sequestro, as atividades do crime organizado e, sobretudo, homicídios. Na verdade, quando falamos de violência urbana tem que se falar de "violências", porque há múltiplas modalidades. Eu poderia dizer que estamos falando de quatro modalidades básicas. Uma delas é o crescimento desse crime da delinquência, fato que vem ocorrendo no Brasil desde a década de 1970; o crescimento dos crimes contra o patrimônio e sobretudo dos crimes contra a pessoa em particular, dos homicídios. Quer dizer, o crescimento dos homicídios no Brasil, se você fizer uma série histórica de 1970 até recentemente, vai ver que as taxas sempre foram crescentes. A segunda modalidade são os crimes conectados com a chamada criminalidade organizada. Durante muito tempo, para nós, criminalidade organizada estava centralizada em torno da questão do tráfico de drogas e das operações imediatamente conectadas com o chamado tráfico de drogas. É o sequestro de pessoas, roubos, que são operações que muitas vezes visam acumular moeda, dinheiro, para financiar as atividades do tráfico. O tráfico necessita de dinheiro vivo, de moeda, não faz operações bancárias em geral, e você precisa produzir isso. Quando você não consegue fazê-lo no circuito de compra e venda das mercadorias, tem que ter as atividades subsidiárias; então, muitas vezes, um jovem envolvido e com dívidas no tráfico tem que fazer outra atividade para poder cobrir isso. E essas são operações complexas. Vemos que hoje o crime organizado é bem mais complexo do que imaginamos. O crime organizado é um conceito que vem muito da esfera policial, mas ele tem dimensão social e política muito complexa. E que não se restringe ao Brasil: o fluxo de capitais é cada vez mais internacionalizado e globalizado. Além da delinquência comum e do crime organizado nessas diferentes facetas, uma terceira modalidade são as graves violações de direitos humanos, que envolve ataques à integridade de pessoas, não por elas serem pessoas, mas por serem portadoras de determinadas identidades agrupais, quer dizer, por serem mulheres, crianças, negros, pertencerem a grupos ligados à sexualidade e são atacados por causa dessas condições. O que está em jogo não é o fato de ela ser uma pessoa e ter o seu direito à vida e à integridade física, mas o fato de que os seus direitos foram atacados em função de pertencer a esses grupos, que na verdade são estigmatizados, são objetos de preconceito. Então há uma dimensão de graves violações aos direitos humanos e, claro, ligado a isso, a violência policial, as ações repressivas, violentas, que não respeitam a dignidade e direitos de quem quer que seja, então essa é a terceira modalidade. A quarta, sobre a qual eu diria que é muito importante e que não possui muitos estudos, são conflitos nascidos nas relações interpessoais que, muitas vezes, acabam em desfecho de mortes. São conflitos domésticos, brigas 
de vizinhos, de casais, entre pais e filhos, brigas nas ruas. E, no meio disso, essas situações que têm se destacado nos últimos anos, que é justamente a exacerbação da intolerância, que beira à violência. Então poderíamos dizer que estamos em uma sociedade que, ao mesmo tempo em que acena para a democracia, para o respeito às instituições, à legalidade etc. é também uma sociedade muito violenta. Em alguns momentos que os conflitos se tornam exacerbados, a intolerância se torna também mais exacerbada ocorrendo, então, o apelo à violência, inclusive à chamada violência fatal.

\section{$C \mathcal{E} E$ : A intolerância é um efeito da violência?}

SA: Eu acho que elas se alimentam reciprocamente. A sociedade brasileira é uma sociedade internamente diferenciada, desigual e hierarquizada, desde a colônia até os nossos dias. Quer dizer, a democracia ainda não logrou reduzir as desigualdades num patamar em que a convivência democrática permita o respeito às diferenças e à diversidade. Que homens e mulheres, adultos e crianças, brancos e negros, ricos e pobres, todos eles possam ter respeito à sua dignidade, às suas características grupais, e também conviver com os outros, ou seja, ter um extrato de solidariedade comum, que faz com que eu possa me sentir solidário com a dor do outro, mesmo que eu não seja branco, mulher etc. A sociedade brasileira é uma sociedade que tem um laço autoritário. Em muitos momentos de exacerbação de conflitos, há um sentimento de que a sociedade funciona mal, porque ela é muito heterogênea. E que, portanto, se ela fosse mais homogênea, se as pessoas pensassem, vamos dizer, "todos como eu penso", talvez a sociedade fosse diferente. $\mathrm{Na}$ origem da intolerância está a ideia de que você reivindica o seu modo de pensamento como o modo certo de viver, o modo certo de a sociedade funcionar, sem respeitar outras possibilidades, outros modos de ser. Quando você acha que alguém na sua casa, que auxilia nos seus trabalhos domésticos, não tem os mesmos direitos a ter opiniões como você, estamos numa sociedade perigosamente violenta. Então, o que eu quero dizer é que a intolerância vai nascendo disso, desse sentimento de que a diversidade é um obstáculo; que toda diferença deve ser suportável, desde que ela seja hierarquizada, desde que haja aqueles que estejam, na verdade, na posição de comando, e aqueles que estejam na posição de serem comandados. Quanto mais você exacerba este sentimento de que a hierarquia é desejável, e quanto mais — vamos dizer assim — polarizada ela for, melhor você intensifica esse sentimento de intolerância. Quem está embaixo tem que obedecer, e quem está em cima manda. Ponto. Nenhuma sociedade democrática se sustenta dessa maneira. Então eu acho que a intolerância está muito ligada com esse sentimento, de que a diferença interna na sociedade é insuportável; que quanto mais homogênea, quanto mais as pessoas pensarem igual, quanto mais elas forem rígidas em seus valores etc., mais ela terá ordem. Nós sabemos, ao longo da história, a que isso leva: aos regimes autoritários por um lado, ao enraizamento do autoritarismo na sociedade por outro, e leva, muitas vezes, aos regimes ditatoriais, em que qualquer contestação, qualquer divergência é, na verdade, recusada com o uso da força. 
CEEE: Nos últimos meses temos observado no Brasil, principalmente via redes sociais, uma eclosão de manifestações negativas, descontroladas e violentas da sociedade a respeito dos mais diversos assuntos, da política à luta de classes, até o fundamentalismo religioso. Essas reações estão sendo chamadas de "discurso do ódio". Como o senhor analisa esse momento?

SA: Não se trata de um fenômeno recente. Tal coisa já vem sendo gestada há certo tempo. Claro que ele tem ondas que se manifestam, em alguns momentos, com maior intensidade. Por exemplo, quando existe um crime violento, que é cometido com graus de violência e crueldade muito grandes, isso tende a mobilizar opiniões. As pessoas se sentem agredidas e começam a verbalizar o sentimento de que isso é inaceitável. Embora atos violentos sejam inaceitáveis, não é com mais violência que você contém a violência. Nós estudamos aqui no Núcleo de Estudos da Violência as ações dos esquadrões da morte. Até meados dos anos 1990, ocorriam as chamadas ações dos esquadrões, que matavam suspeitos de terem cometido crimes, ou pessoas envolvidas no crime, mas que haviam se desentendido com quadrilhas, gangues e a polícia. E eles eram mortos. Muitas vezes, matavam-se pessoas que estavam próximas, o esquadrão chegava, matava todo mundo, mas se verificavam certos interditos morais: não era permitido matar crianças ou pessoas idosas, não se entrava na casa das pessoas atirando em todo mundo. A partir de meados dos anos 1990 terminam os interditos. Se há uma suspeita, e se a pessoa visada está dentro de casa, o criminoso entra e mata todo mundo. Não importa se é criança, adulto, velho, doente etc. Alguma coisa mudou no sistema brasileiro, quer dizer, certo limite moral foi rompido, e quando isso acontece, significa que você não é mais solidário com a dor e com o sofrimento do outro. E, em última instância, que não considera o outro pertencente à humanidade. Então a vida dele pode ser dispensada. O ódio justifica isso. Se observarmos o que foram, por exemplo, os regimes autoritários dos anos 1930 na Europa, o que fermentou foi essa sensação. Ou seja, judeus, ciganos, homossexuais etc. não tinham a mesma natureza que eu, ariano. Então, posso dispensá-los, a vida deles é dispensável. Estamos vivendo um momento agora que isso está se exacerbando. As razões? Difícil saber. Temos que entender que a sociedade brasileira mudou muito, e a democracia mudou muito a sociedade brasileira. Para alguns setores conservadores da sociedade brasileira, o fato de que houve uma extensão de direitos para um número maior de cidadãos provenientes de vários grupos sociais, sobretudo das chamadas classes dos trabalhadores urbanos de baixa renda, é como se a sociedade estivesse num caminho perigoso. As pessoas falam que a direita, os conservadores estão aparecendo e manifestando esse ódio. Na verdade, sempre houve essa direita e sempre houve esse ódio. É que a democracia e os acontecimentos recentes no Brasil, a corrupção, a ingovernabilidade fizeram com que as pessoas perdessem o pudor de vir a público e manifestar as opiniões. Enfim, eu não sei dizer se existe mais ou menos ódio. Acontece que, hoje, temos uma espécie de fluxo de manifestações, de ódio e de intolerância que certamente estavam contidos até recentemente. Acho que tem a ver também com a crise institucional, política, econômica e, no momento em que você está em situação de crise econômica e as pessoas percebem que o 
futuro está incerto, elas começam também a avaliar o que as mantém vivas e se apegam aos seus valores: religiosos, morais, culturais e assim por diante. Quando esses valores ficam de tal maneira "encastelados" na sua própria lógica interna, e não se comunicam com os outros, irrompe a aceitação da intolerância, do medo, e do desejo que tudo que é diferente seja eliminado.

$C \mathcal{E} E$ : E como o senhor entende o papel dos meios de comunicação nessa crise de intolerância que temos presenciado no país?

SA: Os meios de comunicação têm um papel ambíguo. Se você pegar, por exemplo, a mídia eletrônica, a mídia impressa, as redes sociais também, elas são um retrato da sociedade. O que significa isso? Ao mesmo tempo em que existem forças sociais comprometidas com esclarecimento, com a divulgação de uma cultura da paz, uma cultura dos direitos humanos, da tolerância, você tem também forças sociais que apelam para a intolerância, a violência, a ameaça. A mídia reflete essas duas pontes. Há uma mídia que, na verdade, estimula a sensação de ódio, de intolerância, e também tem uma mídia que procura criar um espaço público de debate, de conhecimento. Eu acho que a mídia é parte da sociedade; ao mesmo tempo em que dá vazão a opiniões, digamos, antidemocráticas, que comprometem a convivência coletiva, ela também cria espaços de educação, de discussão, de conhecimento, de divulgação de informações. O problema é o desequilíbrio. Muitas vezes você tem mais expressões de ódio do que de solidariedade, cooperação, conhecimento, esclarecimento.

$C \mathcal{E} E$ : As pesquisas sobre violência sempre ocuparam lugar de destaque no mundo acadêmico. Como o Núcleo de Estudos da Violência está abordando a violência no mundo atual?

SA: Nós vamos fazer um grande projeto agora, que faz parte do programa Cepid, que é financiado pela Fapesp, que, depois de vinte e tantos anos estudando as várias formas de violência - porque a gente sempre trabalhou em um tripé: primeiro, os fatos da sociedade, as modalidades de violência etc.; segundo, as representações sobre justiça, direitos, direitos humanos, como é que as pessoas veem o papel dos governantes; e terceiro, analisando como o Estado responde a essas violências, por meio de políticas públicas, por exemplo. Analisando esse tripé, chegamos a um elemento comum, o fato de que a democracia no Brasil, apesar de jovem, não conseguiu fixar para os cidadãos, a lei como instrumento de contenção de violência, de criação de uma sociedade fundada nos direitos humanos, na tolerância, na convivência pacífica, na solidariedade, na cooperação, a despeito dos conflitos. Então, nós estamos fazendo um estudo sobre legitimidade. Como é que os cidadãos, de diferentes grupos sociais, extratos econômicos, etários, homens e mulheres, inclusive adolescentes, como eles obedecem ou não às leis. Por que obedecer? E por que não obedecer? É um estudo longitudinal - vamos acompanhar uma população da cidade um período - com o objetivo de verificar como, ao longo do tempo, ocorrem as relações entre governantes e governados. Sobretudo em áreas específicas da administração pública, que é 
a Segurança Pública, Educação e Saúde. Por exemplo, vamos acompanhar um cidadão que foi objeto de violência e que vai até a delegacia dar queixa. Observar se ele registra a ocorrência, se é bem recebido, vamos ver como é que os funcionários públicos respondem. Desse estudo longitudinal tentaremos entender por que há muita desconfiança em relação às leis e em relação às instituições. E isso parece ser um elemento fundamental para compreender por que a violência se mantém na sociedade brasileira, a despeito dos avanços democráticos.

CEEE: Recentemente, a Câmara dos Deputados aprovou em sessão bastante polêmica a redução da maioridade penal. $O$ discurso majoritário sobre o assunto resvala na afirmação de que a sociedade é refém dos jovens infratores e criminosos. Por outro lado, os dados mostram que os jovens pobres e negros são as maiores vítimas de assassinatos. Como o senhor pode nos explicar essa esquizofrênica situação social?

SA: Eu, pessoalmente, acompanhando os fatos, durante certo tempo fiz pesquisa de jovens com a delinquência. A minha pesquisa é antiga, mas eu suspeito que o envolvimento de jovens com o mundo do crime não mudou muito nesses últimos 20 anos. Pode ter havido alguns jovens que tenham se tornado mais e mais violentos, e que talvez mereçam um tratamento tutelar diferenciado do que é dado hoje. Mas não a redução da maioridade penal. Porque nós já temos uma punição nesse país. Quando você mesma diz que a maioria dos jovens negros e pobres são vítimas dos homicídios, estamos querendo dizer com isso que já há um processo punitivo aqui, só que pior ainda, sem fundamento legal. Eu também acho que não está inteiramente comprovado que a redução da maioridade penal seja solução para conter o envolvimento de jovens e adolescentes no mundo do crime, mesmo no crime violento. Não há nenhuma comprovação; em alguns países, aparentemente isso funcionou e em outros, não. Então nós não podemos transformar isso numa política. Além disso, a política da redução da maioridade penal é uma política que não trata do essencial. O que é o essencial? É a ausência de políticas preventivas, porque não se discute prevenção no Brasil, programas, projetos. Nós desenvolvemos um projeto aqui no Núcleo, a partir de uma ampla revisão de literatura sobre prevenção, e que mostra que o programa mais adequado, que por meio de ações deliberadas, educativas, de assistência, você reforça o vínculo da mãe com seus filhos nos dois primeiros anos. Esse reforço, sobretudo das mães mais jovens, daí atenção para a chamada gravidez precoce, quando você reforça esse vínculo, essa criança vai ter menos inclinações para se envolver em atos de violência. E os pais estarão sempre mais preocupados em acompanhar a história dessa criança. Isso é um programa, que foi examinado aqui, estamos publicando um livro sobre essa questão. Então, a redução da maioridade aparece como quimera. Só que ela só poderia funcionar se outras políticas preventivas tivessem se mostrado ineficientes. Qual é a política preventiva hoje? Colocar na Fundação Casa, que pode até dar certo apoio, mas não é "a” política preventiva. A política preventiva tem que estar reforçando os vínculos da criança na família, na escola e nas instituições promotoras de lazer, educação, para que ela possa ser 
uma criança em que a inclinação dela para o mundo do crime seja minimizada. Então eu sou literalmente contra, eu acho que é uma política eleitoreira da pior espécie, que não vai produzir resultados e, supostamente para alguns setores da sociedade, temerosos de que esse fenômeno está crescendo, pode aparecer como solução. Eu confesso que não estou convencido.

$C \mathcal{E} E$ : A escola é apontada como mãe de todas as soluções para os graves problemas sociais, inclusive a violência. Na sua opinião, a escola pode se encarregar de mais esta tarefa de enfrentar a violência?

SA: Eu acho que a escola tem um papel muito importante, mas ela tem que ser inteiramente repensada. Para que a escola seja um espaço de aprendizado, ensino, pesquisa, convivência e aprendizado dos direitos fundamentais, ela precisa ser um lugar atraente, um lugar em que as crianças queiram ficar, queiram aprender. Para isso, é preciso que se tenha uma revolução na educação básica no Brasil. O que temos em dados é que as taxas de evasão e de repetência são altas, e isso mostra que o papel que a escola poderia ter não está sendo cumprido. Também não podemos achar que tudo se resolve na escola; a escola é parte do processo, não a solução única. Eu acho que temos que pensar a escola no contexto de outros programas, de esportes, lazer, turismo local etc., onde as crianças possam ser reconhecidas, valorizadas e se sintam identificadas no espaço onde elas estão circulando, estão aprendendo. Fora isso, precisa vontade política e cooperação da sociedade, que parte da sociedade esteja convencida em investir substantivamente em programas inovadores, que pensem a criança de um modo distinto. É preciso envolver, sobretudo, a sociedade civil organizada; muitos de nós teremos que doar uma parte de seu tempo para programas, ações, atividades de inserção dessas crianças adolescentes em programas adequados.

$C \mathcal{E} E$ : O senhor afirmou, no início dessa entrevista, que vivemos "ondas" de violência. $\mathrm{O}$ que devemos esperar do futuro?

SA: Por enquanto, eu estou achando que o nosso cenário é cada vez um cenário de agravamento. Pode piorar mais. Até hoje eu não vi movimentos concretos para que possa ter uma melhora. Em muitos países onde se reduziu a violência, foi elaborado um programa estratégico. Nós queremos reduzir os homicídios em $10 \%$ nos próximos cinco anos; em 25\% nos próximos 40 anos; para isso, o que nós vamos fazer? Recrutamento e reforma da polícia, modificar a legislação... se não houver um planejamento estratégico de curto, médio, longo prazos, não há como enfrentar essas situações. A questão da lei e da ordem não pode ser pensada como uma questão puramente de governo, é uma questão de Estado, que envolve qualidade de vida, sobrevivência interna da sociedade, significa viver a possibilidade de ser atacado, seja contra a sua integridade física, contra seus direitos fundamentais, contra seu patrimônio, qualquer coisa do gênero. E eu acho que, entre as políticas que estão sendo desenvolvidas, nenhuma delas aborda esse fato de modo concreto. 